\title{
Inflammation after cataract extraction and intraocular lens implantation in patients with rheumatoid arthritis
}

\author{
Toshihiko Matsuo, Miki Fujiwara, Nobuhiko Matsuo
}

\begin{abstract}
Aims-The purpose of this study was to examine whether preoperative activity of rheumatoid arthritis influences the extent of anterior chamber inflammation after cataract extraction and intraocular lens implantation.

Methods-The medical records of 23 consecutive patients (33 eyes) with rheumatoid arthritis, who underwent cataract extraction with intraocular lens implantation, were reviewed during a 4 year period from April 1990 to March 1994.

Results-Eleven patients who still showed a $1+$ level of aqueous cells 1 month after the surgery had significantly higher titres of rheumatoid factor preoperatively, compared with the other 12 patients who showed no aqueous cells $(p=0.0019$, Mann-Whitney U test). The persistence of aqueous cells also had a significant correlation with extracapsular cataract extraction compared with phacoemulsification $\left(\mathbf{p}=0.0391, \chi^{2}\right.$ test). Multivariate analysis showed that the titre of rheumatoid factor was the more significant element to determine the persistent aqueous inflammation. All the eyes, except for four which had a macular hole, optic disc atrophy, or retinitis pigmentosa gained visual acuity of $20 / 30$ or better. The aqueous cells cleared 3 months after the surgery and left no complications in any of the eyes.

Conclusion-Intraocular lens implantation is basically a safe procedure for patients with rheumatoid arthritis, although postoperative aqueous inflammation tends to be persistent in patients with high titres of rheumatoid factor.

(Brf Ophthalmol 1995; 79: 549-553)
\end{abstract}

Department of

Ophthalmology,

Okayama University

Medical School,

Okayama City, Japan

T Matsuo

N Matsuo

Eye Clinic, Kurashiki Kosai Hospital, Kurashiki City, Japan M Fujiwara

Correspondence to: Toshihiko Matsuo, MD, Department of

Departunent of Ophthalmology, Okayama University Medical School, 2-5-1 Shikata-cho, Okayama City,

Okayama 700, Japan.

Accepted for publication

10 January 1995
Rheumatoid arthritis is a chronic systemic disease manifested by symmetrical arthritis of small joints, rheumatoid nodules, and a positive test for serum rheumatoid factor (IgG, IgM, or IgA class autoantibodies directed against the Fc fragments of IgG). ${ }^{12}$ The ocular manifestations of rheumatoid arthritis include keratoconjunctivitis sicca (Sjögren's syndrome), ${ }^{3}$ episcleritis and scleritis, ${ }^{45}$ corneal melting disease, ${ }^{67}$ and retinal vasculitis. ${ }^{8-10}$ Iritis or iridocyclitis seen in patients with rheumatoid arthritis is not a direct consequence of the disease but is secondary to other ocular complications such as scleritis. ${ }^{11-13}$

Patients with rheumatoid arthritis often have posterior and anterior subcapsular cataract which quickly reduces their vision to the level low enough to disturb reading and ambulation. ${ }^{14}$ Cataract is caused principally by long term use of corticosteroid hormones in the treatment of rheumatoid arthritis. ${ }^{14}$ Cataract extraction and intraocular lens implantation have been thought to be a safe procedure in patients with rheumatoid arthritis with no ocular complications. We noted, however, postoperative intraocular inflammation after cataract extraction and intraocular lens implantation varied markedly from patient to patient. To elucidate clinical factors which predispose some patients to have the severer postoperative intraocular inflammation, we reviewed patients with rheumatoid arthritis who underwent cataract extraction and intraocular lens implantation.

\section{Patients and methods}

We reviewed medical records of 23 consecutive patients with rheumatoid arthritis who had undergone cataract extraction with intraocular lens implantation at Kurashiki Kosai Hospital during a 4 year period from April 1990 to March 1994. The hospital has a special clinic for the treatment of rheumatoid arthritis. All the patients included in the study satisfied the diagnostic criteria for rheumatoid arthritis published by the American Rheumatism Association in $1987 .{ }^{15}$

Planned extracapsular cataract extraction or phacoemulsification was performed based on cataract maturity and intraocular lenses were fixed in the capsular bag with the aid of hyaluronic acid (Healon, Pharmacia). One week before the cataract surgery, each patient underwent systemic evaluations including blood pressure, kidney and liver function tests, fast blood sugar, erythrocyte sedimentation rates, complete blood cell counts, serum levels of C-reactive protein, immunoglobulins, $\alpha 2$ globulins, complements (C3 and C4), and rheumatoid factor. Titres of rheumatoid factor and levels of C-reactive protein were determined by nephelometry (turbidimetric immunoassay).

Postoperative follow up examinations were recorded at 3 days, 1 week, 1 month, and 3 months after the surgery. At each examination were recorded visual acuity, refractive errors, keratometric readings, keratic precipitates, aqueous cells and flares, anterior vitreous cells, presence or absence of fibrin formation, clearness of the posterior capsule and intraocular lens, iris atrophy, intraocular pressure, and findings in the fundus and angle. Levels of cells 
Table 1 Medical management of rheumatoid arthritis before cataract surgery and other systemic complications

\begin{tabular}{|c|c|c|c|}
\hline \multirow{2}{*}{$\begin{array}{l}\text { Case nol } \\
\text { sex/ } \\
\text { age (years) }\end{array}$} & \multicolumn{2}{|c|}{ Drugs for rheumatoid arthritis } & \multirow[b]{2}{*}{ Other systemic complications } \\
\hline & $\begin{array}{l}\text { Prednisolone } \\
\text { (mg/day) }\end{array}$ & Others & \\
\hline $1 / F / 63$ & 5 & Bucillamine & Hyperlipidaemia \\
\hline $2 / \mathrm{F} / 72$ & 5 & Bucillamine & No \\
\hline $3 / \mathrm{F} / 68$ & No & D-penicillamine & Diabetes mellitus \\
\hline $4 / \mathrm{F} / 70$ & No & No & Hypertension \\
\hline $5 / \mathrm{F} / 78$ & No & Bucillamine, lobenzarit & Diabetes mellitus \\
\hline $6 / \mathrm{F} / 78$ & No & Lobenzarit & Diabetes mellitus \\
\hline $7 / \mathrm{F} / 81$ & 5 & No & No \\
\hline $8 / \mathrm{F} / 60$ & 5 & Methotrexate & No \\
\hline $9 / F / 75$ & 5 & Bucillamine & Hypertension \\
\hline $10 / F / 67$ & $2 \cdot 5$ & D-penicillamine & No \\
\hline $11 / \mathrm{F} / 78$ & 5 & Bucillamine & No \\
\hline $12 / \mathrm{F} / 77$ & 5 & D-penicillamine & Lung cancer \\
\hline $13 / F / 69$ & 5 & Bucillamine & Hypertension \\
\hline $14 / F / 69$ & 5 & No & Hypertension \\
\hline $15 / F / 76$ & No & Gold & No \\
\hline $16 / F / 66$ & 5 & Gold & Asthma \\
\hline $17 / F / 74$ & 5 & No & Hypertension, amyloidosis \\
\hline $18 / \mathrm{F} / 81$ & 5 & Bucillamine & Hypertension, heart failure \\
\hline $19 / \mathrm{M} / 78$ & $7 \cdot 5$ & No & No \\
\hline $20 / F / 65$ & No & No & No \\
\hline $21 / F / 59$ & $2 \cdot 5$ & Methotrexate & Hypertension, angina pectoris \\
\hline $22 / F / 65$ & No & Bucillamine, D-penicillamine & Hypertension \\
\hline $23 / F / 75$ & No & Bucillamine, gold & No \\
\hline
\end{tabular}

$M=$ male $; \mathrm{F}=$ female

and flares in the anterior chamber and anterior vitreous were recorded according to the grading system of Hogan et al. ${ }^{16}$ Briefly, both cells and flares were graded increasingly from $1+$ to $4+$.

Each patient was given postoperatively a combination of $0 \cdot 1 \%$ betamethasone sodium phosphate, $0.1 \%$ diclofenac sodium, and $0.3 \%$ ofloxacin eye drops four times a day for 4 weeks after the surgery.

For statistical analyses, the eye that underwent cataract surgery earlier was chosen in each patient when both eyes had been operated on. ${ }^{17} 18$ Statistical analyses were done with a software STATVIEW (Macintosh) package.

\section{Results}

Thirty three eyes of 23 consecutive patients with rheumatoid arthritis underwent cataract surgery during the period. Planned extracapsular cataract extraction was performed in 16 eyes and phacoemulsification was done in the other 17 eyes. Extracapsular cataract extraction was concentrated in the initial phase because patients with maturer cataract underwent the surgery earlier. The cataract surgery was free of intraoperative complications, including capsular rupture, and intraocular lenses were implanted in the capsular bag of all the eyes. The age of the patients at surgery varied from 59 to 81 years and all the patients except for one (case 19) were female (Table 1). The follow up periods were from 3 months to 4 years.

Patients had the history of rheumatoid arthritis ranging from 5 to 33 years. Most of the patients received a low dose of prednisolone $(2 \cdot 5-7 \cdot 5 \mathrm{mg})$ every day combined with other medications such as gold (auranofin), methotrexate, lobenzarit, bucillamine, or D-penicillamine for rheumatoid arthritis before the surgery (Table 1). Doses of the medication, including prednisolone for rheumatoid arthritis, were not changed during a 3 month period after cataract surgery in all patients. Three patients had diabetes mellitus and seven patients had essential hypertension. Prednisolone was not given to these three diabetic patients. No patient showed exfoliation syndrome, or the previous history of uveitis, episcleritis, scleritis, or keratoconjunctivitis sicca.

All the eyes except four eyes gained best corrected visual acuity of $20 / 30$ or better after cataract surgery. A macular hole, optic disc atrophy, or retinitis pigmentosa was found in these four eyes with poor visual outcome (Fig 1). One eye (case 6) developed transient elevation of intraocular pressure up to $33 \mathrm{~mm} \mathrm{Hg} 3$ days after surgery, which returned to normal within 4 days without any medication. Other complications directly linked to the surgery, including cystoid macular oedema, were absent. One patient (case 12) died of lung cancer 6 months after surgery, and another patient (case 19) developed endogenous fungal endophthalmitis in both eyes and died in the course of intravenous hyperalimentation for general debilitation 5 months after surgery.

No eye had preoperative inflammation in the anterior chamber. All the eyes had some degree of aqueous inflammation 3 days and 1 week after the cataract surgery (Table 2). Sixteen eyes still had a $1+$ level of aqueous cells 1 month after surgery, while the other 17 eyes had no inflammation. Aqueous inflammation completely cleared in all eyes 3 months after surgery.

The extent of aqueous inflammation both 3 days and 1 week after the surgery did not have any correlation with preoperative activity of rheumatoid arthritis shown by white blood cell counts, erythrocyte sedimentation rates, serum levels of C-reactive proteins, or serum titres of rheumatoid factor. In other words, higher activity of rheumatoid arthritis did not necessarily lead to more marked aqueous inflammation immediately after intraocular lens implantation.

The presence or absence of aqueous cells 1 month after surgery is plotted against preoperative serum titres of rheumatoid factor,

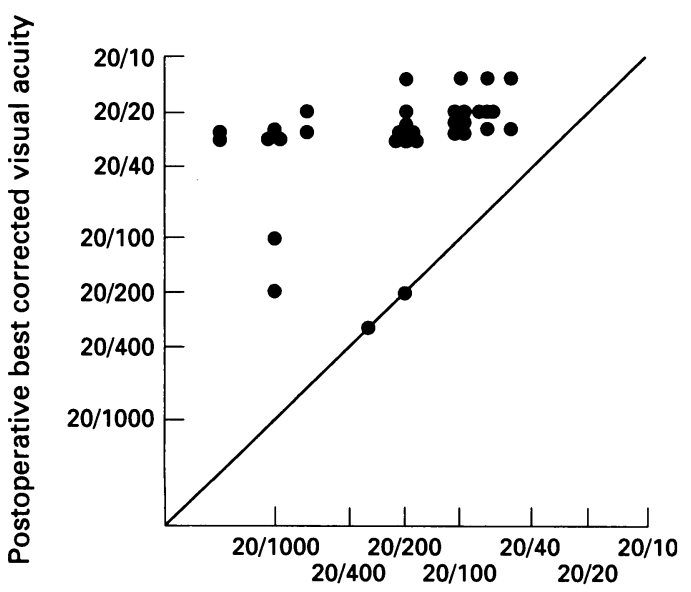

Preoperative best corrected visual acuity

Figure 1 Scattergram showing preoperative and postoperative best corrected visual acuity in the 33 eyes of 23 patients with rheumatoid arthritis who underwent cataract extraction and intraocular lens implantation. All eyes except for four (which had a macular hole, optic disc atrophy, or retinitis pigmentosa) gained visual acuity of $20 / 30$ or better. 


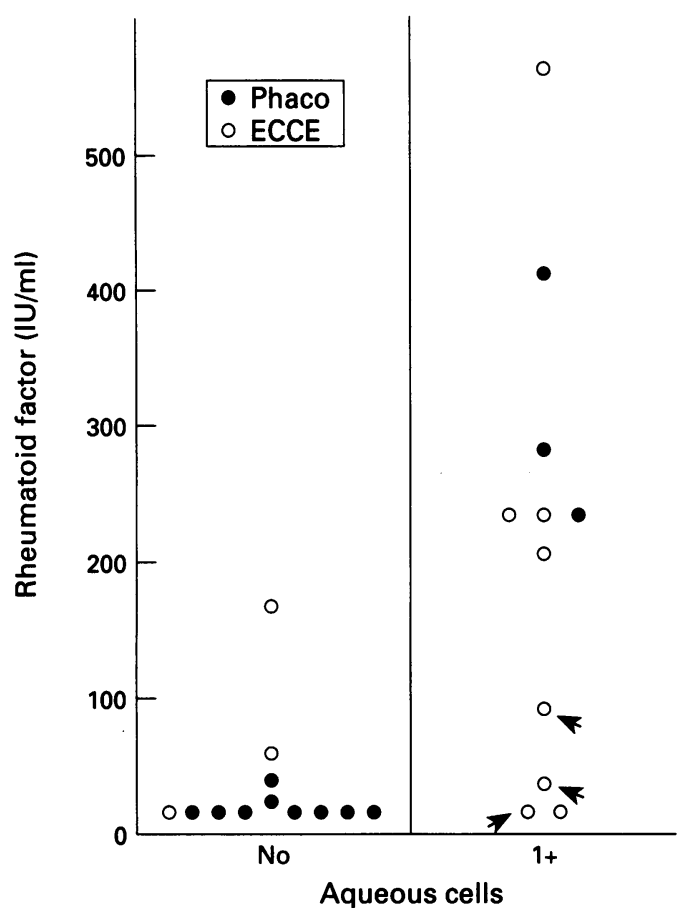

Figure 2 Preoperative serum titres of rheumatoid factor are significantly higher in patients with a 1+ level of aqueous cells compared with patients with no aqueous cells 1 month after cataract surgery ( $p=0.0019$, MannWhitney $U$ test). Arrowheads indicate patients with diabetes mellitus who show aqueous cells despite lower titres of rheumatoid factor. Eyes which underwent surgery earlier were chosen, when both eyes were operated on. $E C C E=$ extracapsular cataract extraction;

Phaco $=$ phacoemulsification

erythrocyte sedimentation rates, serum levels of C-reactive protein, and white blood cell counts (Fig 2). Patients with no aqueous cells had lower titres of rheumatoid factors (median 17 $\mathrm{IU} / \mathrm{ml}$ ), while those with aqueous cells had the

Table 2 Rheumatic activity and aqueous cells after cataract surgery

\begin{tabular}{|c|c|c|c|c|c|c|c|c|}
\hline \multirow{2}{*}{$\begin{array}{l}\text { Case nol } \\
\text { eye }\end{array}$} & \multicolumn{3}{|c|}{ Aqueous cells } & \multirow{2}{*}{$\begin{array}{l}E S R \\
(\mathrm{~mm} / \mathrm{h})\end{array}$} & \multirow{2}{*}{$\begin{array}{l}C R P \\
(m g / d l)\end{array}$} & \multirow{2}{*}{$\begin{array}{l}R F \\
(I U / m l)\end{array}$} & \multirow{2}{*}{$\begin{array}{l}W B C \\
\left(\times 10^{6} /\right)\end{array}$} & \multirow{2}{*}{$\begin{array}{l}\text { Surgica } \\
\text { methods }\end{array}$} \\
\hline & 3 Days & 1 Week & 1 Month & & & & & \\
\hline $1 / \mathrm{OS}$ & $3+$ & $1+$ & $1+$ & 49 & 6.47 & 235 & 11100 & ECCE \\
\hline $2 / O D$ & $3+$ & $1+$ & $1+$ & 28 & 0.38 & 566 & 7600 & ECCE \\
\hline IOS & $3+$ & $2+$ & $1+$ & 37 & $6 \cdot 31$ & 560 & 9900 & ECCE \\
\hline $3 / \mathrm{OS}$ & $2+$ & $1+$ & $1+$ & 20 & $0 \cdot 25$ & 36 & 6700 & ECCE \\
\hline $4 / \mathrm{OS}$ & $2+$ & $1+$ & $1+$ & 8 & 0.25 & 17 & 4900 & $\bar{E} C \overline{C E}$ \\
\hline $5 / O D$ & $3+$ & $2+$ & $1+$ & 68 & $11 \cdot 4$ & 92 & 7700 & $\overline{\mathrm{ECCE}}$ \\
\hline $6 / O D$ & $1+$ & $1+$ & $1+$ & 67 & $6 \cdot 18$ & 17 & 11400 & ECCE \\
\hline IOS & $3+$ & $1+$ & $1+$ & 73 & $2 \cdot 20$ & 16 & 13300 & ECCE \\
\hline $7 / O D$ & $2+$ & $1+$ & $1+$ & 20 & 3.68 & 207 & 8500 & ECCE \\
\hline IOS & $2+$ & $2+$ & $1+$ & 20 & $3 \cdot 68$ & 207 & 8500 & ECCE \\
\hline $8 / \mathrm{OS}$ & $2+$ & $1+$ & $1+$ & 72 & 0.97 & 270 & 2100 & Phaco \\
\hline /OD & $2+$ & $2+$ & $1+$ & 33 & 0.46 & 288 & 2000 & ECCE \\
\hline 9/OD & $3+$ & $2+$ & $1+$ & 62 & 0.95 & 235 & 4500 & ECCE \\
\hline $10 / \mathrm{OD}$ & $2+$ & $1+$ & No & 40 & 2.53 & 28 & 7300 & Phaco \\
\hline $11 / \mathrm{OD}$ & $3+$ & $1+$ & No & 24 & $5 \cdot 45$ & 17 & 6300 & Phaco \\
\hline IOS & $2+$ & $2+$ & No & 7 & $3 \cdot 24$ & 17 & 4600 & ECCE \\
\hline $12 / \mathrm{OS}$ & $1+$ & $1+$ & No & 96 & $15 \cdot 4$ & 61 & 10300 & ECCE \\
\hline $13 / \mathrm{OS}$ & $1+$ & $1+$ & No & 40 & 0.29 & 170 & 10900 & ECCE \\
\hline $14 / \mathrm{OD}$ & $3+$ & $1+$ & No & 8 & 0.82 & 16 & 4100 & Phaco \\
\hline $15 / \mathrm{OD}$ & $3+$ & $1+$ & No & 40 & 0.43 & 16 & 5900 & ECCE \\
\hline $16 / 0 S$ & $2+$ & $1+$ & No & 40 & $4 \cdot 29$ & 16 & 11000 & Phaco \\
\hline 17/OD & $1+$ & $1+$ & No & 7 & 0.70 & 17 & 4500 & Phaco \\
\hline IOS & $3+$ & $2+$ & No & 17 & 0.59 & 17 & 6200 & Phaco \\
\hline $18 / \mathrm{OS}$ & $1+$ & $1+$ & No & 53 & $2 \cdot 44$ & 17 & 5700 & Phaco \\
\hline /OD & $1+$ & $1+$ & No & 66 & $1 \cdot 20$ & 17 & 6100 & Phaco \\
\hline $19 / 0 S$ & $2+$ & $1+$ & $1+$ & 60 & 0.87 & 231 & 9400 & Phaco \\
\hline IOD & $3+$ & $1+$ & $1+$ & 32 & 0.28 & 202 & 8600 & Phaco \\
\hline $20 / O D$ & $2+$ & $1+$ & $1+$ & 68 & 1.89 & 412 & 5900 & Phaco \\
\hline $21 / \mathrm{OS}$ & $2+$ & $1+$ & No & 77 & $5 \cdot 17$ & 38 & 6100 & Phaco \\
\hline $22 / \mathrm{OS}$ & $1+$ & $1+$ & No & 10 & 0.45 & 17 & 6100 & Phaco \\
\hline IOD & $2+$ & $1+$ & No & 20 & 0.31 & 17 & 4800 & Phaco \\
\hline $23 / \mathrm{OD}$ & $1+$ & $1+$ & No & 5 & 0.76 & 16 & 9800 & Phaco \\
\hline IOS & $1+$ & $1+$ & No & 6 & 0.57 & 16 & 7500 & Phaco \\
\hline
\end{tabular}

ECCE = extracapsular cataract extraction; Phaco=phacoemulsification; OD=right eye; OS=left eye; $\mathrm{ESR}=$ erythrocyte sedimentation rate; $\mathrm{CRP}=\mathrm{C}$-reactive protein; $\mathrm{RF}=$ rheumatoid factor; $\mathrm{WBC}=$ white blood cell count; $\mathrm{IU}=$ international unit. higher titres (median $231 \mathrm{IU} / \mathrm{ml}$ ). The difference between the titres in the two groups was statistically significant $(p=0.0019$, MannWhitney $U$ test). When the patients with aqueous cells were divided further arbitrarily into two groups: one group (seven patients) with titres of rheumatoid factors of $200 \mathrm{IU} / \mathrm{ml}$ or higher and the other group (four patients) with the titres of $100 \mathrm{IU} / \mathrm{ml}$ or lower, three patients out of four with the lower titres had diabetes mellitus (Fig 2). This indicates that persistent aqueous inflammation in these patients with the low titres of rheumatoid factors could be attributed to diabetes mellitus. Erythrocyte sedimentation rates, serum levels of C-reactive protein, or white blood cell counts did not correlate with the presence or absence of aqueous cells 1 month after the surgery.

Ten patients underwent cataract surgery in both eyes separately. The presence or absence of aqueous inflammation 1 month after surgery was consistent between both eyes in all 10 patients. Extracapsular cataract extraction was performed in 12 out of 16 eyes which showed persistent aqueous inflammation 1 month after surgery, while phacoemulsification was performed in 13 out of 17 eyes which showed no aqueous cells at the same time. When one eye operated on earlier was chosen for statistical analysis in patients who underwent surgery in both eyes, the persistence of aqueous cells 1 month after surgery had a significant correlation with extracapsular cataract extraction compared with phacoemulsification (Fisher's exact, $p=0.0391, \chi^{2}$ test).

Multivariate analysis of the data showed that the titre of rheumatoid factor was the more significant element to determine the persistent aqueous inflammation than was the difference in the surgical procedure $(p=0.0008$ versus $\mathrm{p}=0.0046$, multiple regression analysis).

\section{Discussion}

Serum titres of rheumatoid factors, erythrocyte sedimentation rates, and serum levels of acute phase reactants including C-reactive protein are known to correlate with activity of rheumatoid arthritis. Patients with higher titres of rheumatoid factor, increase of erythrocyte sedimentation rates, and elevation of C-reactive protein have the severer and more progressive disease with extra-articular manifestations. ${ }^{1}$

The present study demonstrated that the presence or absence of aqueous inflammation 1 month after cataract extraction and intraocular lens implantation had a positive correlation with preoperative serum titres of rheumatoid factors. The patients with higher titres of rheumatoid factor developed persistent aqueous inflammation 1 month after surgery. However, no correlation was found between the presence or absence of aqueous cells and other factors including erythrocyte sedimentation rates, Creactive protein, and white blood cell counts. This discrepancy can be explained by the fact that erythrocyte sedimentation rates, C-reactive proteins, and white blood cell counts are influenced not only by activity of rheumatoid arthritis but also by inflammation of other origin. 
The aqueous cells cleared 3 months after surgery even in those patients who showed aqueous inflammation 1 month after surgery. No patient developed major surgical complications including fibrin deposition, posterior iris synechia, persistent elevation of intraocular pressure, or cystoid macular oedema during the follow up period. Therefore, cataract extraction and intraocular lens implantation seem to be safe procedures for patients with rheumatoid arthritis.

Cataract surgery in patients with various types of uveitis has been reported. ${ }^{19-39}$ A new technique, with complete aspiration of the lens cortex after extracapsular extraction or phacoemulsification of the nucleus and implantation of intraocular lenses in the capsular bag, is a basically safe procedure even in patients with the previous experience of uveitis. The rate of recurrence of uveitis after cataract surgery varies from report to report. A conclusion drawn from these reports is that good visual outcome with low postoperative inflammation in cataract surgery depends upon the selection of patients based on the type of uveitis and its activity. One series described two patients who had developed scleritis and iritis previously in the course of rheumatoid arthritis who underwent cataract extraction with intraocular lens implantation and had a good outcome without any complications. ${ }^{30}$ The present study showed that the absence of earlier iritis or scleritis in patients with rheumatoid arthritis did not necessarily ensure the absence of persistent inflammation after cataract extraction.

The best way to avoid persistent postoperative inflammation in patients with rheumatoid arthritis is to postpone cataract surgery and wait until the activity of the disease decreases. In cases where cataract surgery has to be performed in spite of rather high disease activity, preoperative and postoperative oral administration of corticosteroids can alleviate inflammatory reaction in the anterior chamber, although not totally. Recently designed intraocular lenses with a heparin modified surface could be used in place of polymethylmethacrylate lenses in a group of patients at high risk of postoperative severe inflammation. ${ }^{40-43}$

In the present study, patients with many variables were analysed retrospectively. For example, patients underwent either extracapsular cataract extraction or phacoemulsification. These different surgical methods naturally influenced the extent of postoperative aqueous inflammation. Extracapsular cataract extraction appears to have been performed more frequently on patients with higher titres of rheumatoid factor, possibly because these patients had more mature cataract and were operated on in the initial phase of the study. Although the persistent aqueous inflammation in this series could be attributed in part to extracapsular cataract extraction, multivariate analysis clearly demonstrated that the titre of rheumatoid factor was the more significant element in determining the delayed aqueous inflammation.

Furthermore, the patients took different combinations of the medication for rheumatoid arthritis and had systemic diseases other than rheumatoid arthritis. Oral prednisolone can reduce postoperative inflammation, while patients with diabetes mellitus usually have persistent and severe inflammation after cataract surgery. Further study will be required to confirm the positive correlation between rheumatic activity and persistent aqueous inflammation after cataract surgery in patients with rheumatoid arthritis.

We thank Dr Yozo Tsuchida for his assistance in the statistical analysis.

1 Lipsky PE. Rheumatoid arthritis. In: Wilson JD, Braunwald E, Isselbacher KJ, Petersdort RG, Martin JB, Fauci AS, et al, eds. Harrison's principles of internal medicine. 12th ed. New York: McGraw-Hill, 1991: 1437-43.

2 Jabs DA. Ocular manifestations of the rheumatic diseases. In: Tasman W, Jaeger EA, eds. Duane's clinical ophthalmology. Volume 5. Chapter 26. Philadelphia: JB Lippincott, 1992: 1-5.

3 Williamson J. Incidence of eye disease in cases of connective tissue disease. Trans Ophthalmol Soc UK 1974; 94: 742-52.

4 Jayson MIV, Jones DEP. Scleritis and rheumatoid arthritis. Ann Rheum Dis 1971; 30: 343-7.

5 McGavin DDM, Williamson J, Forrester JV, Foulds WS, Buchanan WW, Dick WC, et al. Episcleritis and scleritis. A study of their clinical manifestations and association with rheumatoid arthritis. $B r \mathcal{F}$ Ophthalmol 1976; 60: 192-226.

6 Brown SI, Grayson M. Marginal furrows. A characteristic corneal lesion of rheumatoid arthritis. Arch Ophthalmol 1968; 79: 563-7.

7 Foster CS, Forstot SL, Wilson LA. Mortality rate in rheumatoid arthritis patients developing necrotizing scle-
ritis or peripheral ulcerative keratitis. Ophthalmology 1984; 91: 1253-63.

8 Meyer E, Scharf J, Miller B, Zonis S, Nahir M. Fundus lesions in rheumatoid arthritis. Ann Ophthalmol 1978; 10: 1583-4.

9 Martin MFR, Scott DGI, Gilbert C, Dieppe PA, Fasty DI. Retinal vasculitis in rheumatoid arthritis. $B M \mathcal{F} 1981 ; 282$ : 1745-6.

10 Matsuo T, Koyama T, Morimoto N, Umezu H, Matsuo N. Retinal vasculitis as a complication of rheumatoid arthritis. Ophthalmologica 1990; 201: 196-200.

11 Hogan MJ, Kimura SJ, Thygeson P. Uveitis in association with rheumatism. Arch Ophthalmol 1957; 57: 400-13.

12 Lenoch F, Kralik V, Bartos J. 'Rheumatic' iritis and iridocyclitis. Ann Rheum Dis 1959; 18: 45-8.

13 Kimura SJ, Hogan MJ, O'Connor GR, Epstein WV. Uveitis and joint diseases. Clinical findings in 191 cases. Arch Ophthalmol 1967; 77: 309-16.

14 Black RL, Oglesby RB, Sallmann L von, Bunim JJ. Posterior subcapsular cataracts induced by corticosteroids in patients with rheumatoid arthritis. $\mathcal{F A M A} 1960 ; 174$ : in patients

15 Arnett FC, Edworthy SM, Bloch DA, McShane DJ, Fries $\mathrm{JF}$, Cooper NS, et al. The American rheumatism associaJF, Cooper NS, et al. The American rheumatism associaton 1987 revised criteria for the classification of
toid arthritis. Arthritis Rheum 1988; 31: 315-24.

16 Hogan MJ, Kimura SJ, Thygeson P. Signs and symptoms of uveitis. I. Anterior uveitis. Am f Ophthalmol 1959; 47 (Part II): 155-70.

17 Newcombe RG, Duff GR. Eyes or patients? Traps for the unwary in the statistical analysis of ophthalmological studies. Br f Ophthalmol 1987; 71: 645-6.

18 Smith R. Christmas editorial 1991. Br F Ophthalmol 1991; 75: 705 .

19 Foster CS, Fong LP, Singh G. Cataract surgery and intraocular lens implantation in patients with uveitis. intraocular lens implantation in

20 Gee SS, Tabbara KF. Extracapsular cataract extraction in Fuchs' heterochromic iridocyclitis. Am f Ophthalmol 1989; 108: 310-4.

21 Chung YM, Yeh TS. Intraocular lens implantation following extracapsular cataract extraction in uveitis. Ophthalmic Surg 1990; 21: 272-6.

22 Hooper PL, Rao NA, Smith RE. Cataract extraction in uveitis patients. Surv Ophthalmol 1990; 35: 120-44.

23 Brinkman CJ, Los GJ, Breebaart AC. Cataract extraction in patients with chronic posterior uveitis. Acta Ophthalmol 1990; 68: 151-4.

24 Michelson JB, Friedlaender MH, Nozik RA. Lens implant surgery in pars planitis. Ophthalmology 1990; 97: 1023-6.

surgery in pars planitis. Ophthalmology 1990; 97: 1023-6.
25 Jones NP. Extracapsular cataract surgery with and without intraocular lens implantation in Fuchs' heterochromic
inten intraocular lens implantation
uveitis. Eye 1990; 4: 145-50.

26 Jakeman CM, Jordan K, Keast-Butler J, Perry S. Cataract surgery with intraocular lens implantation in Fuchs' heterochromic cyclitis. Eye 1990; 4: 543-7.

27 Baarsma GS, de Vries J, Hammudoglu CD. Extracapsular cataract extraction with posterior chamber lens implantation in Fuchs's heterochromic cyclitis. $\mathrm{Br} \mathcal{F}$ Ophthalmo 1991; 75: 306-8. 
28 Loewenstein A, Bracha $R$, Lazar $M$. Intraocular lens implantation in an eye with Behcet's uveitis. $f$ Cataract Refract Surg 1991; 17: 95-7.

29 Okinami S, Iwasaki Y, Matsumura M. Intraocular lens implantation in eyes with uveitis. Rinsho Ganka (Fpn $\mathcal{F}$ Clin Ophthalmol) 1991; 45: 81-4.

30 Foster RE, Lowder CY, Meisler DM, Zakov ZN. Extracapsular cataract extraction and posterior chamber intraocular lens implantation in uveitis patients. Ophthalmology 1992; 99: 1234-41.

31 Ando Y, Nagamoto T, Muraki Y, Suzuki S, Kamizono J, Soushi S. IOL implantation in patients with uveitis. Ganka Shujutsu (f Fpn Soc Ophthalmic Surgeons) 1992; 5: 603-9.

32 Kamata K, Ohara K, Okubo A, Sasaki H. Intraocular lens implantation in cataractous eyes with endogenous uveitis.

33 Aoyama Y, Ogino N. Posterior chamber intraocular lens implantation in uveitis patients. Ganka Shujutsu (f fpn Soc implantation in uveitis patients. Ganka

34 Foster CS, Barrett F. Cataract development and cataract surgery in patients with juvenile rheumatoid arthritis-associated iridocyclitis. Ophthalmology 1993; 100: 809-17.

35 Kaufman AH, Foster CS. Cataract extraction in patients with pars planitis. Ophthalmology 1993; 100: 1210-7.

36 Tessler $\mathrm{HH}$, Farber MD. Intraocular lens implantation versus no intraocular lens implantation in patients with chronic iridocyclitis and pars planitis. Ophthalmology 1993; 100: 1206-9.
37 Akova YA, Foster CS. Cataract surgery in patients with sarcoidosis-associated uveitis. Ophthalmology 1994; 101: 473-9.

38 Higuchi $M$, Ino $K$, Ishimaru $H$, Yamamoto $T$, Ohtsaka $H$. Cataract surgery with intraocular lens implantation in uveitis. Rinsho Ganka (Fpn 7 Clin Ophthalmol) 1994; 48: uveitis.

39 Okinami S, Hiroishi G, Saitou I, Iwaki M, Ogino N, Matsumura $M$, et al. Intraocular lens implantation in eyes with uveitis. Rinsho Ganka (Fpn f Clin Ophthalmol) 1994; 48: 739-44.

40 Ygge J, Wenzel M, Philipson B, Fagerholm P. Cellular reactions on heparin surface-modified versus regular PMMA lenses during the first postoperative month. A doublemasked and randomized study using specular microphotography. Ophthalmology 1990; 97: 1216-24.

41 Philipson B, Fagerholm P, Calel B, Grunge A, Hallnas K, Lydahl E, et al. Heparin surface modified intraocular lenses. A one-year follow-up of a safety study. Acta lenses. A one-year follow-
Ophthalmol 1990; 68: 601-3.

42 Percival $P$. Use of heparin-modified lenses in high-risk cases for uveitis. Dev Ophthalmol 1991; 22: 80-3.

43 Borgioli DM, Coster DJ, Fan RFT, Henderson J, Jacobi KW, Kirkby GR, et al. Effect of heparin surface modification of polymethylmethacrylate intraocular lenses on signs of postoperative inflammation after extracapsular cataract extrion. One-year rults af a double-masked multicenter study. Ophthalmology 1992; 99: 1248-55. 